\title{
Gastro-oesophageal reflux and worse asthma control in obese children: a case of symptom misattribution?
}

\author{
Jason E Lang, ${ }^{1}$ Jobayer Hossain, ${ }^{2}$ Janet T Holbrook, ${ }^{3}$ W Gerald Teague, ${ }^{4}$ \\ Benjamin D Gold, ${ }^{5}$ Robert A Wise, ${ }^{6}$ John J Lima ${ }^{7}$
}

- Additional material is published online only. To view please visit the journal online (http://dx.doi.org/10.1136/ thoraxjnl-2015-207662)

For numbered affiliations see end of article.

\section{Correspondence to} Professor Jason E Lang, Division of Pulmonary \& Sleep Medicine, Nemours Children's Hospital, 13535 Nemours Parkway, Orlando, FL 32827, USA; jason.lang@nemours.org

Received 2 August 2015 Revised 22 December 2015 Accepted 4 January 2016 Published Online First 1 February 2016

\section{SLinked}

- http://dx.doi.org/10.1136/ thoraxjnl-2015-207379

\section{CrossMark}

To cite: Lang JE, Hossain J, Holbrook JT, et al. Thorax 2016;71:238-246.

\section{ABSTRACT}

Background Obese children for unknown reasons report greater asthma symptoms. Asthma and obesity both independently associate with gastro-oesophageal reflux symptoms (GORS). Determining if obesity affects the link between GORS and asthma will help elucidate the obese-asthma phenotype.

Objective Extend our previous work to determine the degree of associations between the GORS and asthma phenotype.

Methods We conducted a cross-sectional study of lean (20\%-65\% body mass index, BMI) and obese $(\geq 95 \%$ BMI) children aged 10-17 years old with persistent, early-onset asthma. Participants contributed demographics, GORS and asthma questionnaires and lung function data. We determined associations between weight status, GORS and asthma outcomes using multivariable linear and logistic regression. Findings were replicated in a second well-characterised cohort of asthmatic children.

Results Obese children had seven times higher odds of reporting multiple GORS (OR=7.7, 95\% Cl 1.9 to 31.0 , interaction $p$ value $=.004$ ). Asthma symptoms were closely associated with GORS scores in obese patients $(r=0.815$, $p<0.0001)$ but not in leans $(r=0.291, p=0.200$; interaction $p$ value $=0.003$ ). Higher GORS scores associated with higher FEV1-per cent predicted ( $p=0.003$ ), lower airway resistance $(R 10, p=0.025)$, improved airway reactance ( $\mathrm{X} 10, \mathrm{p}=0.005)$ but significantly worse asthma control (Asthma Control Questionnaire, $\mathrm{p}=0.007$ ). A significant but weaker association between GORS and asthma symptoms was seen in leans compared with obese in the replicate cohort.

Conclusion GORS are more likely to associate with asthma symptoms in obese children. Better lung function among children reporting gastro-oesophageal reflux and asthma symptoms suggests that misattribution of GORS to asthma may be a contributing mechanism to excess asthma symptoms in obese children.

\section{INTRODUCTION}

Obese children report more severe asthma symptoms and have heightened asthma-related healthcare usage compared with similar lean children, ${ }^{1-5}$ yet obesity is not consistently associated with worse objective markers of asthma. ${ }^{6-9}$ These inconsistent findings may stem from confounding variables (such as age of onset, gender, atopy status, co-morbidities and symptom perception), attribution error

\section{Key messages}

What is the key question?

- How are gastro-oesophageal reflux symptoms associated with subjective asthma symptoms and objective asthma measures among lean and obese children with asthma?

\section{What is the bottom line?}

- Interventions focused on helping obese children and adolescents decipher true asthma from co-morbidities are likely to improve disease control and patient satisfaction, and reduce healthcare usage and medication side effects.

\section{Why read on?}

- Our data suggest that most obese children with asthma experience some gastro-oesophageal reflux symptoms which may be misattributed to asthma among obese but not lean children, and contribute to the excess asthma symptoms reported in obese children.

(attributing obesity-related exercise limitations to asthma thus making obese asthma appear more severe or treatment-resistant) and misclassification bias (eg, studying obese patients without true asthma). Gastro-oesophageal reflux disease (GORD) is highly prevalent in both asthmatics ${ }^{10}$ and the obese $^{1112}$ for which anti-reflux drugs are frequently prescribed. ${ }^{13}$ We recently reported that excess dyspnoea and short-acting $\beta$-agonist (SABA) use in obese asthmatics were associated with gastrooesophageal reflux symptoms (GORS). ${ }^{14}$ The role of gastro-oesophageal reflux (GOR) and anti-reflux medications in the management of asthma is much debated. ${ }^{15-17}$ The 2015 Global Initiative for Asthma guidelines recommend evaluating for GOR particularly in obese patients with uncontrolled asthma. ${ }^{18}$ Plausible mechanisms exist for GOR to incite asthma symptoms including: microaspiration and oesophageal or pharyngeal nerve stimulation leading to reflex airway constriction or mediator release. ${ }^{19} 20$ Oesophageal $\mathrm{pH}$ probe monitoring coupled with patient-reported symptoms have shown a close association between documented reflux events and asthma symptoms. ${ }^{21}$ Gastric acid blockers and GORD surgery have shown 
inconsistent improvements in asthma among patients with symptomatic GORD. Conversely, it is also plausible for episodic airflow obstruction caused by asthma to induce oesophageal pressure changes resulting in GOR. A third possibility relates to the fact that GOR and asthma have considerable symptom overlap. Asthmatic children may have difficulty deciphering the aetiology of chest symptoms and may attribute GORS mistakenly to asthma ('misattribution'), thus contributing to an epidemiologic link between the two conditions.

Recently, we reported that overweight/obese children with asthma display poorer asthma control and a pattern of asthma symptoms that was distinct from leaner patients. ${ }^{14}$ Overweight/ obese children reported more asthma symptoms, but had reduced airway inflammation and airway reactivity compared with leans. Overweight/obese children reported more frequent episodes of shortness-of-breath and $\beta$-agonist use. These findings appeared to be partially mediated through excess gastrooesophageal symptoms reported in the overweight/obese children. The overweight children could have had worse asthma symptoms mediated by excess GOR, or they could have reported greater asthma symptoms due to misattribution of GORS. This report extends our prior work by analysing the relationships among obesity, GORS and both subjective and objective asthma measures including impulse oscillometry (IOS) and a replicate cohort.

Misattribution of symptoms generally, and misattribution to asthma specifically, may be common in children. Weinberger ${ }^{22}$ and Seaar ${ }^{23}$ have separately reported that it is commonplace for dyspnoea (resulting from normal cardiopulmonary limitation) to be misattributed to asthma and treated with SABAs. This demonstrates a potentially wider problem in Paediatrics of nonspecific symptoms such as exertional dyspnoea or non-specific cough to be misattributed to asthma, particularly when an asthma diagnosis is already present. Short-acting $\beta 2$ agonists are the most commonly used bronchodilators for asthma, and have the side effect of relaxing the lower oesophageal sphincter, ${ }^{24} 25$ which would be expected to promote oesophageal reflux. Considering (1) the lack of clarify surrounding the obese-asthma phenotype, (2) the difficulty many children have in understanding and verbalising symptoms and (3) the high prevalence of GORS in the obese, we sought to systematically evaluate GOR and asthma symptoms and lean and obese children. We hypothesise that GOR contributes to asthma reporting particularly among obese children.

\section{METHODS}

\section{Participant selection}

Children between 10 and 17 years of age with asthma and receiving daily controller therapy were enrolled through the Nemours multispecialty Paediatric asthma clinic in Jacksonville, Florida between 2008 and 2010. Inclusion methods have been previously described. ${ }^{14}$ Briefly, children with body mass index (BMI) <20th percentile or in the 65th-84th percentile range were excluded to reduce misclassification. Asthma was defined by physician-diagnosis plus evidence of airway hyperresponsiveness. $^{26} 27$ Participants were excluded if they had a smoking history, been on daily oral steroids, required a change in controller therapy in the past 8 weeks, had any illnesses in the past 4 weeks or had a significant chronic disease. Further details are included in the online supplementary material.

\section{Clinical data}

Up to three clinic visits were conducted. Participants signed an institutional review board-approved parental permission form and minor assent. Participants completed staff-directed, structured interviews and questionnaires providing demographics and past asthma and medical history. Participants underwent a physical examination and anthropometric measurements. Exposure to environmental tobacco smoke was measured on a 4-level ordinal scale based on the interview question: Does anyone at your home smoke? $1=$ no one, $2=$ only outside, $3=$ rarely inside and $4=$ inside.

\section{Symptom and quality-of-life analyses}

Asthma symptom control was assessed at visit 1 using the modified Asthma Control Questionnaire (ACQ6) ${ }^{28}$ and Asthma Control Test (ACT). ${ }^{29} 30$ Asthma-related quality-of-life was measured using the Paediatric Asthma Quality of Life Questionnaire $^{31} 32$ and the Paediatric Caregiver's Asthma Quality of Life Questionnaire. ${ }^{33}$ Properties of the asthma control scores, symptom scores and asthma quality of life scores can be found in the online supplementary material.

\section{Gastro-oesophageal symptoms}

Gastrointestinal symptoms were measured using the paediatric patient GERD Symptom Assessment Questionnaire (GSAQ) which is a 10 -item tool ${ }^{26} 34$ that has been validated for assessing children's GORD and digestive symptoms. There are nine core subscales that evaluate frequency and severity of symptoms using ordinal integer scales (0-7) from the previous 7 days. A composite individual symptom score was computed for each subscale which is the product of frequency and severity scores (ranging from 0 to 49 ), with a higher score suggesting worse disease.

\section{Lung function testing}

Participants completed spirometry (Jaeger MasterScreen, San Diego, California, USA) and IOS (Jaeger MasterScreen Impulse Oscillometry System, CareFusion Technologies, San Diego, California, USA) adhering to recommended American Thoracic Society standards ${ }^{35} 36$ and using a standardised IOS protocol based on manufacturer instructions. ${ }^{37}$ Participants also completed FE $_{\mathrm{NO}}$ (Sievers 280i NOA analyzer, Boulder, Colorado, USA) manoeuvres according to recommended standards. ${ }^{38}$ Participants completed a methacholine challenge by experienced staff using the 10 Provocholine concentrations dosing scheme with a five-breath dosimeter protocol. ${ }^{39}$

\section{Replication cohort}

Replication of GSAQ and asthma symptom (ACQ) associations were attempted in 306 children with poorly controlled asthma (ages 5-17) without previous GOR disease who participated in the Study of Acid-Reflux in Childhood Asthma. ${ }^{26}$ GSAQ and ACQ were collected following a 2 to 8 -week run-in prior to randomisation. Further details of the replication cohort can be found in the online supplementary material.

\section{Statistical analysis}

Study variables were summarised by tertile of GSAQ score and by BMI group (BMI 20th-65th percentiles vs BMI $\geq 95$ th percentile). Children with a BMI between the 65 th-94th percentiles were excluded from the primary analysis to better depict the difference between leans and obese patients. Quantitative interval variables were summarised using mean, SD and number of subjects while ordinal variables were summarised by median and intraquartile range. Categorical variables were summarised by numbers of subjects and percentages. The Fisher exact test was used for comparing categorical variables between groups, 
while a Student's t or Wilcoxon-Mann-Whitney U test (whichever was appropriate) was used to compare quantitative variables between groups. To assess the effect across GSAQ tertiles, quantitative variables underwent an analysis of variance with contrast to test for trend, while the Cochran-Armitage test was used to evaluate the same effect in categorical variables. We used Pearson's correlation coefficient to evaluate relationships between GSAQ (and subscales) and ACQ (and subscales). Analyses of covariance were used to detect the effect of BMI status on various asthma symptom control measures. Variables chosen a priori for the model included age, race, ethnicity, gender and atopy status and variables significantly associated with asthma control or lung function. Variables were dropped if they were not found to be significantly associated ACQ with simple linear regression at the $\mathrm{p}<0.05$ level. Assumptions were checked before using a model and appropriate steps were taken in case of any violation of assumptions. All tests were two-tailed at a level of significance of 0.05 . A level of significance of $<0.01$ was chosen when assessing correlations between subscales. The statistical package SAS V.9.3 (SAS Institute, Cary, North Carolina, USA) was used.

\section{RESULTS}

\section{Characteristics of participants}

A total of 74 children with asthma were screened for eligibility. Fifty six children (23 obese, 12 overweight and 21 lean) were enrolled and $96 \%$ conducted all three clinic visits. The screening procedures and baseline characteristics according to BMI status have been previously published. ${ }^{14}$ Baseline characteristics of all participants completing the study $(n=56)$ according to

Table 1 Patient characteristics by GSAQ score tertiles

\begin{tabular}{|c|c|c|c|c|}
\hline \multirow[b]{2}{*}{ Variables, mean (SD) } & \multicolumn{3}{|c|}{ GSAQ tertiles } & \multirow[b]{2}{*}{ p Value } \\
\hline & Q1 & Q2 & Q3 & \\
\hline $\mathrm{N}$ & 18 & 21 & 17 & \\
\hline GER score range & $0-4$ & $6-15$ & $16-223$ & \\
\hline Female, n (\%) & $4(22)$ & $9(43)$ & $9(53)$ & 0.182 \\
\hline Race, n (\%) & & & & 0.934 \\
\hline White & $9(50)$ & $10(48)$ & $7(41)$ & \\
\hline Black & $9(50)$ & $10(48)$ & $9(53)$ & \\
\hline Other & $0(0)$ & $1(5)$ & $1(6)$ & \\
\hline Hispanic/Latino, n (\%) & 1 (6) & $2(10)$ & $2(12)$ & 0.857 \\
\hline Gestational age at birth, weeks & $37.7(4.2)$ & $38.8(2.1)$ & $37.8(4.0)$ & 0.903 \\
\hline Age of asthma diagnosis, years & $4.8(4.5)$ & $4.5(3.7)$ & $4.5(3.8)$ & 0.860 \\
\hline BMI $\geq 95$ th percentile, $n(\%)^{*}$ & $8(44)$ & $14(67)$ & $13(76)$ & $<0.05$ \\
\hline \multicolumn{5}{|l|}{ Anthropometric measurest } \\
\hline BMI percentile & $70.2(24.0)$ & $79.3(24.0)$ & $86.9(20.2)$ & 0.036 \\
\hline Waist circumference in $\mathrm{cm}$ & $72.9(18.5)$ & $75.4(15.5)$ & $86.3(16.4)$ & 0.028 \\
\hline Waist-to-height ratio & $0.46(0.12)$ & $0.49(0.08)$ & $0.55(0.11)$ & 0.027 \\
\hline Abdomen-to-height ratio & $0.48(0.11)$ & $0.51(0.09)$ & $0.57(0.11)$ & 0.012 \\
\hline \multicolumn{5}{|l|}{ Environment } \\
\hline ETS quantitative, median (IQR)‡ & $1(1,1)$ & $1(1,2)$ & $2(1,4)$ & 0.016 \\
\hline \multicolumn{5}{|l|}{ What triggers asthma? n (\%) } \\
\hline Tobacco smoke & $9(50)$ & $9(43)$ & $13(76)$ & 0.122 \\
\hline Allergen & $11(61)$ & $16(76)$ & $10(59)$ & 0.904 \\
\hline Viruses (colds) & $8(44)$ & $14(67)$ & $14(82)$ & 0.019 \\
\hline \multicolumn{5}{|l|}{ Co-morbidities } \\
\hline GORD & $2(11)$ & $8(38)$ & $6(35)$ & 0.109 \\
\hline Allergic rhinitis & $15(83)$ & $19(90)$ & $16(94)$ & 0.301 \\
\hline Depression/anxiety & $3(17)$ & $3(14)$ & $4(24)$ & 0.044 \\
\hline \multicolumn{5}{|l|}{ Family history* } \\
\hline Obesity & $9(50)$ & $16(76)$ & $16(94)$ & 0.003 \\
\hline Diabetes & $0(0)$ & $6(28)$ & $5(29)$ & 0.027 \\
\hline Asthma & $8(44)$ & $12(57)$ & $14(82)$ & 0.022 \\
\hline \multicolumn{5}{|l|}{ Controller treatments, $\mathrm{n}(\%)$} \\
\hline ICS-LABA & $8(44)$ & $10(48)$ & $9(53)$ & 0.944 \\
\hline LTRA & $8(44)$ & $10(48)$ & $5(29)$ & \\
\hline \multicolumn{5}{|l|}{ Usage for asthma } \\
\hline Urgent care visits in past year & $1.5(1.54)$ & $1.1(1.5)$ & $1.8(2.1)$ & 0.591 \\
\hline Steroid bursts in past year & $0.83(0.98)$ & $0.86(1.2)$ & $1.2(1.9)$ & 0.391 \\
\hline
\end{tabular}

Values are means (SD) unless noted.

*Cochran-Armitage Trend test for categorical variables.

tAnalysis of variance test for linear trend used for continuous variables.

$\ddagger$ Kruskal-Wallis test.

BMI, body mass index; ETS, environmental tobacco smoke; GORD, gastro-oesophageal reflux disease; GSAQ, GERD Symptoms Assessment Questionnaire; ICS, inhaled corticosteroids;

LABA, long-acting $\beta$-agonists; LTRA, leukotriene receptor antagonist.

Bolded figures represent statistical significance at the level of $p<0.05$. 
Table 2 Asthma outcomes by GSAQ score tertile

\begin{tabular}{|c|c|c|c|c|c|c|}
\hline \multirow[b]{2}{*}{ Variables, mean (SD) } & \multicolumn{3}{|l|}{ GSAQ tertile } & \multirow[b]{2}{*}{ p Value } & \multirow[b]{2}{*}{ p Value* } & \multirow[b]{2}{*}{$\mathrm{p}$ Valuet } \\
\hline & $\mathrm{T} 1$ & $\mathrm{~T} 2$ & T3 & & & \\
\hline$A C Q$, mean (SD) & $0.76(0.78)$ & $0.99(0.46)$ & $1.52(0.82)$ & $0.007 \ddagger$ & 0.025 & 0.090 \\
\hline Morning symptom & $0(0,0)$ & $0(0,1)$ & $1(0,2)$ & $0.007 \S$ & & \\
\hline Activity limitation & $0(0,1)$ & $1(0,1)$ & $2(0,3)$ & 0.069 & & \\
\hline SABA use & $0(0,1)$ & $1(1,1)$ & $1(0,2)$ & 0.109 & & \\
\hline Shortness of breath & $(0,1)$ & $1(1,2)$ & $3(1,4)$ & $<0.001$ & & \\
\hline Wheezing & $0.5(0,1)$ & $1(0,1)$ & $2(1,3)$ & 0.001 & & \\
\hline Awakening & $0(0,0)$ & $0(0,2)$ & $1(0,2)$ & 0.011 & & \\
\hline$A C T$, mean (SD) & $23.0(1.5)$ & $19.6(2.9)$ & $18.8(3.6)$ & $0.002 \ddagger$ & 0.017 & 0.038 \\
\hline Getting as much done & $5(4.5,5)$ & $4.5(4,5)$ & $4(4,5)$ & $0.213 \S$ & & \\
\hline Nocturnal symptoms & $5(5,5)$ & $5(4,5)$ & $5(3,5)$ & 0.165 & & \\
\hline Rate & $4.5(4,5)$ & $4(4,4)$ & $4(3,4)$ & 0.005 & & \\
\hline SABA use & $5(4,5)$ & $3(3,4)$ & $4(3,4)$ & 0.007 & & \\
\hline Shortness of breath & $4(4,5)$ & $4(3,4)$ & $4(3,4)$ & 0.028 & & \\
\hline \multicolumn{7}{|l|}{ Quality of Life } \\
\hline PAQLQ, mean (SD) & $5.9(1.0)$ & $5.3(1.2)$ & $4.4(1.2)$ & $0.0004 \ddagger$ & 0.010 & 0.083 \\
\hline PACQLQ, mean (SD) & $5.7(1.2)$ & $5.3(1.3)$ & $4.9(1.0)$ & $0.053 \ddagger$ & 0.200 & 0.239 \\
\hline \multicolumn{7}{|l|}{ Spirometry } \\
\hline FVC per cent predicted, mean (SD) & $97.8(8.9)$ & $92.7(24.0)$ & $106.6(14.5)$ & $0.140 \ddagger$ & 0.041 & 0.066 \\
\hline Z score & $-0.04(0.49)$ & $-0.32(1.3)$ & $0.44(0.80)$ & & & \\
\hline FEV1 per cent predicted, mean (SD) & $84.7(13.1)$ & $86.7(14.3)$ & $99.9(16.3)$ & $0.003 \ddagger$ & 0.013 & 0.017 \\
\hline Z score & $-0.34(0.83)$ & $-0.21(0.91)$ & $0.62(1.0)$ & & & \\
\hline FEV1 (litres)/FVC (litres) & $75.8(12.3)$ & $77.9(7.8)$ & $82.1(8.9)$ & $0.060 \ddagger$ & 0.317 & 0.417 \\
\hline Z score & $-0.27(1.23)$ & $-0.06(0.78)$ & $0.37(0.90)$ & & & \\
\hline $\mathrm{FE}_{\mathrm{NO}}(\mathrm{ppb})$, mean $(\mathrm{SD})$ & $59.9(50.2)$ & $55.4(58.0)$ & $43.4(32.2)$ & 0.471 & 0.843 & 0.955 \\
\hline Impedance $\left(\mathrm{cm} \mathrm{H} \mathrm{H}_{2} \mathrm{O} / \mathrm{L} / \mathrm{s}\right)$, mean (SD) & $9.0(2.4)$ & $8.4(2.3)$ & $6.7(2.2)$ & 0.007 & 0.032 & 0.011 \\
\hline \multicolumn{7}{|l|}{ Resistance ( $\left.\mathrm{cm} \mathrm{H}_{2} \mathrm{O} / \mathrm{L} / \mathrm{s}\right)$, mean (SD) } \\
\hline R5 & $8.3(2.1)$ & $7.7(2.1)$ & $6.9(3.0)$ & $0.084 \ddagger$ & 0.269 & 0.141 \\
\hline R10 & $6.6(1.5)$ & $6.2(1.7)$ & $5.3(1.5)$ & 0.025 & 0.117 & 0.037 \\
\hline R15 & $5.8(1.3)$ & $5.4(1.6)$ & $5.0(1.3)$ & 0.115 & 0.407 & 0.146 \\
\hline $\mathrm{R} 20$ & $5.4(1.4)$ & $4.9(1.4)$ & $4.9(1.4)$ & 0.304 & 0.658 & 0.363 \\
\hline R25 & $5.3(1.4)$ & $5.0(1.3)$ & $4.7(1.2)$ & 0.208 & 0.576 & 0.274 \\
\hline R35 & $6.0(1.6)$ & $5.5(1.2)$ & $5.1(1.1)$ & 0.069 & 0.240 & 0.131 \\
\hline \multicolumn{7}{|l|}{ Reactance $\left(\mathrm{cm} \mathrm{H}_{2} \mathrm{O} / \mathrm{L} / \mathrm{s}\right)$ ), mean (SD) } \\
\hline X5 & $-3.3(1.7)$ & $-3.1(1.1)$ & $-2.6(1.8)$ & $0.209 \ddagger$ & 0.304 & 0.253 \\
\hline $\mathrm{X} 10$ & $-2.1(1.3)$ & $-1.9(0.9)$ & $-1.0(0.9)$ & 0.005 & 0.013 & 0.013 \\
\hline $\mathrm{X} 15$ & $-1.4(0.9)$ & $-1.3(0.8)$ & $-0.5(0.8)$ & 0.005 & 0.017 & 0.011 \\
\hline $\mathrm{X} 20$ & $-0.7(0.6)$ & $-0.5(0.8)$ & $-0.1(0.7)$ & 0.015 & 0.066 & 0.027 \\
\hline X25 & $0.2(0.6)$ & $0.2(0.7)$ & $0.5(0.6)$ & 0.112 & 0.385 & 0.175 \\
\hline X35 & $1.3(0.6)$ & $1.4(0.7)$ & $1.5(0.7)$ & 0.368 & 0.874 & 0.560 \\
\hline $\mathrm{AX}\left(\mathrm{cm} \mathrm{H}_{2} \mathrm{O} / \mathrm{L}\right)^{* *}$ & $29.5(17.6)$ & $27.5(15.2)$ & $15.1(14.9)$ & $0.015 \ddagger$ & 0.042 & 0.020 \\
\hline$F$ res $(1 / s)^{* *}$ & $24.4(3.8)$ & $23.3(5.3)$ & $19.4(7.4)$ & 0.014 & 0.064 & 0.004 \\
\hline \multicolumn{7}{|l|}{ Airway reactivity } \\
\hline BDR, no. $(\%)$ & 7 (39) & $7(33)$ & $5(29)$ & $0.553+\dagger$ & & \\
\hline FEV1 per cent change & 14 & 13 & 10 & $0.395 \ddagger$ & & \\
\hline $\mathrm{PC} 20(\mathrm{mg} / \mathrm{mL})$ & $0.7(0.3,1.3)$ & $1.2(0.4,4.4)$ & $1.2(0.2,3.1)$ & $0.249 \S$ & & \\
\hline
\end{tabular}

${ }^{*}$ p Value after adjustment for BMI percentile.

tp Value after adjustment for BMI percentile, sex, second-hand tobacco smoke exposure and presence or depression or anxiety.

$¥$ Analysis of variance test for linear trend.

§Kruskal-Wallis test for subscales.

IMore negative numbers correspond to worse lung function.

** Lower values correspond to worse lung function.

t+Cochran-Armitage Trend test for categorical variables.

ACQ, Asthma Control Questionnaire, subscales under ACQ are 0-6 point integer scales with a higher score indicating worse asthma; ACT, asthma control test, subscales under ACT are

1-5 point integer scales with a lower score indicating worse asthma; $A X$, area of reactance; BDR, bronchodilator reversibility ( $\geq 12 \%$ improvement in FEV1); $F$ res, resonant frequency;

GSAQ, GERD Symptoms Assessment Questionnaire; PACQLQ, paediatric asthma caregiver's quality of life questionnaire; ppb, parts per billion; PAQLQ, paediatric asthma quality of life questionnaire; PC20, provocation concentration eliciting a 20\% FEV1 drop; SABA, short-acting $\beta$ agonist; $R$, resistance; $X$, reactance.

Bolded figures represent statistical significance at the level of $p<0.05$.

GSAQ score tertiles are shown in table 1. GSAQ scores were not associated with age, race, ethnicity, age of asthma diagnosis or controller treatment. GSAQ scores were associated with central obesity and systolic blood pressure (data not shown). Following adjustment for obesity, the association between blood pressure and GOR was eliminated. Higher GSAQ tertile was 
associated with a greater prevalence of viral infections triggering asthma, higher prevalence of child anxiety/depression, greater environmental tobacco smoke exposure and family history of obesity.

\section{GORS associate with worse asthma symptoms but better lung function}

Despite these negative health effects, GSAQ score was associated with significantly better lung function with FEV1 improving over increasing GSAQ tertiles, even with adjustment for BMI-percentile (adjusted $\mathrm{p}=0.013$ ) (table 2). Respiratory system resistance (Rrs) and reactance (X, elasticity of lung and thorax) also showed a counterintuitive negative association with higher GSAQ tertiles. Greater GSAQ also did not worsen airway reactivity. The lowest GSAQ tertile group consistently had the least evidence of airway responsiveness (prevalence of bronchodilator reversibility (BDR), per cent FEV1 change following bronchodilator, and PC20) though each was not statistically significant. Worse GSAQ scores did associate with worse asthma symptom reporting and worse asthma-related quality of life (table 2). In both the ACQ and ACT, higher GSAQ scores were associated with worse asthma symptoms, and specifically with the shortness-of-breath subscale in both validated questionnaires. The associations between GSAQ and FEV1 did not depend on obesity status (obesity*GSAQ interaction $p$ value on FEV1=0.903).

\section{Frequency and severity of GORS by obesity status}

Obesity was a strong predictor for GORS reporting in the asthma cohort (figure 1, table 3). GORS were present in the previous week in nearly all $(22 / 23,96 \%)$ of the obese patients $(p=0.042)$, and obese patients had $>7$ times the odds of suffering two or more types of GORS in the previous week compared with leans (OR 7.1, 95\% CI 1.9 to $31.1, \mathrm{n}=44$ ). The most prevalent symptoms were belching/burping (59\%), nausea $(46 \%)$ and difficulty swallowing (39\%). Obese children also reported more severe GORS, particularly related to nausea, difficulty swallowing and night-time abdominal pain.

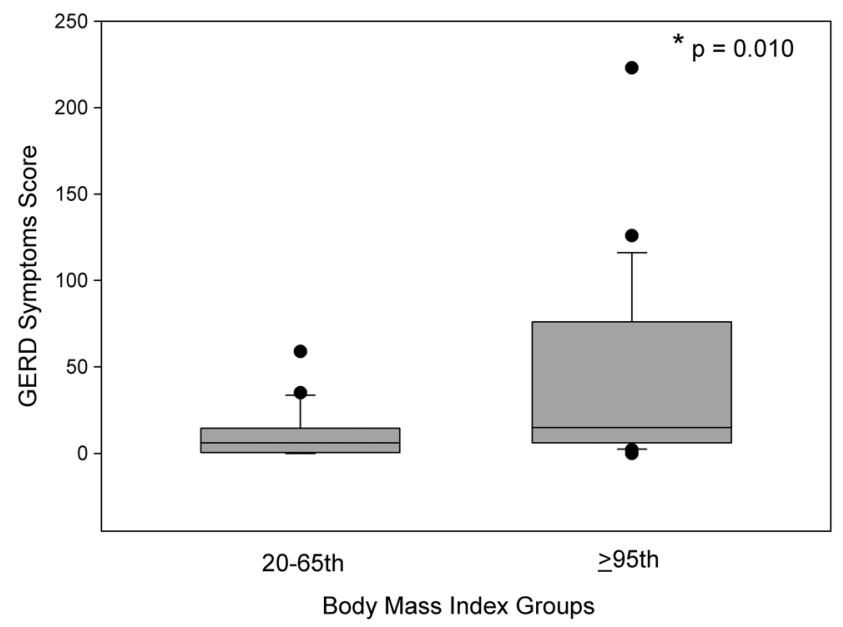

Figure 1 GORD symptom scores measured using the GSAQ among lean (20th-65th percentile BMI) and obese ( $\geq 95$ th percentile BMI) children with asthma. Box plots show median and 25th and 75th percentiles, while whiskers denote 5 th and 95th percentiles. Individual points are outliers. ${ }^{*} p=0.010$, Student's $t$ test. BMI, body mass index; GORD, gastro-oesophageal reflux disease.

\section{Associations between GORS and asthma symptoms}

The close associations between GSAQ scores and asthma symptoms were noted in children who were obese $(r=0.815$, $\mathrm{p}<0.0001)$ but not in children who were lean $(r=0.291$, $\mathrm{p}=0.200$ ) (tables 4 and 5). We noted a statistical interaction between obesity status and the correlation between GSAQ score and ACQ (interaction $\mathrm{p}$ value $=0.003$, figure 2). Among obese asthmatics, total GSAQ scores were highly significantly associated with each subscale of the ACQ ( $p$ values ranged from 0.007 to $<0.0001$ ), with the noted exception of the FEV1 subscale. The closest correlation with total GSAQ score was SABA use subscale $(\mathrm{R}=0.776, \mathrm{p}<0.0001)$. This association between total GSAQ score and SABA use was not present in lean patients $(\mathrm{R}=0.086, \mathrm{p}=0.710)$.

\section{Replication}

There were 306 participants whose data contributed to the replicate analysis. Patient characteristics by GSAQ score tertile are shown in the online supplementary appendix table E1. Obese children in the replicate cohort displayed a moderate association between GSAQ score and asthma control. Unlike in the original cohort, there was an association (although weak) between GSAQ and asthma control in leans. However, the strength of this association increased with increasing BMI (leans: $r=0.317$, $p=0.001$; obese: $r=0.507, p<0.0001)$. As in the original cohort, GSAQ which was associated with worse asthma symptoms was not associated with worse lung function in lean $(\mathrm{r}=0.0508, \mathrm{p}=0.6143)$ or obese $(\mathrm{r}=0.0178, \mathrm{p}=0.864)$ children.

\section{DISCUSSION}

Our study showed that measurement of GORS using the validated GSAQ is closely associated with worse asthma symptoms primarily among obese children. Furthermore, among obese children, GSAQ was particularly strongly associated with shortness of breath and SABA use. Unexpectedly, higher GSAQ scores were closely associated with improved (not worsened) lung function. GORD has been previously reported to occur in $43 \%-87 \%$ of asthmatic children, ${ }^{17}$ and our data suggest that nearly all obese children with asthma experience some type of GOR-related symptom when asked using a validated paediatric questionnaire. Nausea, difficulty swallowing and sleepdisrupting abdominal pain were especially problematic. Taken together, these data appear inconsistent with GOR directly inciting (or resulting from) true asthma, and suggests that a new line of thinking is needed to fully understand the GOR-asthma relationship. GORS, occurring more in obese children, appears to be misattributed to asthma and contributing to the greater asthma reporting among the obese.

Much debate surrounds the 'chicken or egg' problem with GOR and asthma. If GOR is truly inciting asthma, we would expect to see concurrent reductions in airway function. However, GSAQ was closely and consistently associated with better lung function measured using multiple modalities. Few past studies have reported impulse oscillometric measures of lung function in asthmatics with obesity or GOR. Rrs using IOS reflects airway calibre and total Rrs. Therefore, Rrs should increase with asthma. Reactance (reactance of the respiratory system) represents lung recoil and the elastic properties of the lung and thorax. At low frequencies (X5, X10), reactance is affected by peripheral airway obstruction and becomes more negative as airway obstruction increases. All of these measures, plus spirometry and methacholine airway responsiveness, yielded the opposite results expected if GOR was truly 
Table 3 Gastro-oesophageal symptoms among lean and obese children with asthma

\begin{tabular}{|c|c|c|c|}
\hline Variables & BMI 20-65th & BMI $\geq 95$ th & p Value* \\
\hline & 21 & 23 & - \\
\hline GSAQ score, mean (SD) & $10.9(14.6)$ & $43.0(54.5)$ & 0.012 \\
\hline Any symptoms, n (\%) & $15(71)$ & $22(96)$ & 0.042 \\
\hline$\geq 2$ symptoms, $\mathrm{n}(\%)$ & $8(38)$ & $19(83)$ & 0.005 \\
\hline GSAQ range & $0-59$ & $0-223$ & - \\
\hline \multicolumn{4}{|l|}{ Abdominal pain } \\
\hline Frequency scale & $0(0,0)$ & $0(0,1)$ & 0.114 \\
\hline Severity scale & $0(0,0)$ & $0(0,2)$ & 0.112 \\
\hline Composite ISS & $0.6(1.5)$ & $3.4(6.7)$ & 0.072 \\
\hline \multicolumn{4}{|l|}{ Chest pain/heartburn } \\
\hline Frequency scale & $0(0,0)$ & $0(0,2)$ & 0.045 \\
\hline Severity scale & $0(0,0)$ & $0(0,2)$ & 0.059 \\
\hline Composite ISS & $0.5(1.2)$ & $4.8(9.0)$ & 0.042 \\
\hline \multicolumn{4}{|l|}{ Difficulty swallowing } \\
\hline Frequency scale & $0(0,0)$ & $1(0,2)$ & 0.001 \\
\hline Severity scale & $0(0,0)$ & $2(0,2)$ & 0.004 \\
\hline Composite ISS & $0.7(1.7)$ & $4.8(7.3)$ & 0.021 \\
\hline Night-time pain/awakening & $0(0,0)$ & $0(0,0)$ & 0.025 \\
\hline Frequency scale & $0(0,0)$ & $0(0,0)$ & 0.025 \\
\hline Severity scale & $0(0)$ & $1.7(4.7)$ & 0.110 \\
\hline \multicolumn{4}{|l|}{ Composite ISS } \\
\hline \multicolumn{4}{|l|}{ Nausea } \\
\hline Frequency scale & $0(0,1)$ & $1(0,3)$ & 0.026 \\
\hline Severity scale & $0(0,2)$ & $2(0,3)$ & 0.020 \\
\hline Composite ISS & $1.2(2.1)$ & $4.8(6.0)$ & 0.015 \\
\hline \multicolumn{4}{|l|}{ Vomiting/regurgitation } \\
\hline Frequency scale & $0(0,0)$ & $0(0,2)$ & 0.119 \\
\hline Severity scale & $0(0,0)$ & $0(0,3)$ & 0.098 \\
\hline Composite ISS & $0.8(2.4)$ & $5.9(10.4)$ & 0.042 \\
\hline \multicolumn{4}{|l|}{ Burping/belching } \\
\hline Frequency scale & $1(0,4)$ & $2(1,7)$ & 0.145 \\
\hline Severity scale & $1(0,1)$ & $1(1,3)$ & 0.062 \\
\hline Composite ISS & $5.4(8.9)$ & $10.5(14.6)$ & 0.187 \\
\hline \multicolumn{4}{|l|}{ Choking when eating } \\
\hline Frequency scale & $0(0,0)$ & $0(0,1)$ & 0.140 \\
\hline Severity scale & $0(0,0)$ & $0(0,2)$ & 0.084 \\
\hline Composite ISS & $0.8(2.7)$ & $2.8(6.7)$ & 0.214 \\
\hline \multicolumn{4}{|l|}{ Pain after eating } \\
\hline Frequency scale & $0(0,0)$ & $0(0,2)$ & 0.144 \\
\hline Severity scale & $0(0,0)$ & $0(0,2)$ & 0.154 \\
\hline Composite ISS & $0.6(1.6)$ & $4.1(7.9)$ & 0.062 \\
\hline
\end{tabular}

triggering asthmatic airway changes. Alternatively, uncontrolled asthma can induce pressure changes across the lower oesophageal sphincter resulting in GOR. ${ }^{40}$ This mechanism also does not fit with our findings of better lung function in the high GOR tertile.

Other authors have provided evidence that GOR can trigger asthma. Proposed mechanisms include microaspiration and also afferent vagus stimulation with airway changes. Kiljander reported that more severe GOR was associated with increased airway responsiveness. ${ }^{41}$ Allen and Wohl showed that children with asthma and GOR had worse small airway obstruction without reductions in lung volumes compared with children with GOR and no respiratory symptoms. ${ }^{42}$ Several human experimental studies have shown that oesophageal acidification causes airway narrowing and reactivity. ${ }^{20}{ }^{43}$ However, oesophageal afferent and vagal stimulation of airway smooth muscle and mediator influx similarly would be expected to worsen lung function.

In a replicate cohort of asthmatic children with uncontrolled asthma on daily inhaled corticosteroids, we saw the same close association between GSAQ and asthma symptoms in the obese. However, in leans the association was weaker. In neither leans nor obese children was GSAQ associated with reduced lung function. The replicate cohort, though larger in size, may have 
Table 4 Correlation coefficients between asthma and GSAQ score subscales in obese children

\begin{tabular}{|c|c|c|c|c|c|c|c|c|c|c|}
\hline & ACQ & Woken & Morning & Activities & $S O B$ & Wheeze & $S A B A$ & FEV1 & FEV1\% & FEV1/FVC \\
\hline GSAQ score & $0.815(<0.0001)$ & $\begin{array}{l}0.701 \\
(0.0002)\end{array}$ & $\begin{array}{c}0.556 \\
(0.007)\end{array}$ & $\begin{array}{c}0.658 \\
(0.0006)\end{array}$ & $\begin{array}{c}0.555 \\
(0.006)\end{array}$ & $\begin{array}{c}0.734 \\
(<0.0001)\end{array}$ & $\begin{array}{c}0.776 \\
(<0.0001)\end{array}$ & $\begin{array}{l}-0.148 \\
(0.500)\end{array}$ & $\begin{array}{c}0.144 \\
(0.512)\end{array}$ & $\begin{array}{l}-0.050 \\
(0.820)\end{array}$ \\
\hline Abdominal pain & $0.551(<0.010)$ & & & & & & & & & \\
\hline $\begin{array}{l}\text { Chest pain/ } \\
\text { heartburn }\end{array}$ & $0.790(<0.0001)$ & & & & & & & & & \\
\hline $\begin{array}{l}\text { Difficulty } \\
\text { swallowing }\end{array}$ & $0.458(0.037)$ & & & & & & & & & \\
\hline $\begin{array}{l}\text { Night-time pain/ } \\
\text { awakening }\end{array}$ & $0.750(<0.0001)$ & & & & & & & & & \\
\hline Nausea & $0.585(0.005)$ & & & & & & & & & \\
\hline $\begin{array}{l}\text { Vomiting/ } \\
\text { regurgitation }\end{array}$ & $0.546(<0.010)$ & & & & & & & & & \\
\hline Burping/belching & $0.579(0.006)$ & & & & & & & & & \\
\hline $\begin{array}{l}\text { Choking when } \\
\text { eating }\end{array}$ & $0.647(0.002)$ & & & & & & & & & \\
\hline Pain after eating & $0.569(0.007)$ & & & & & & & & & \\
\hline
\end{tabular}

\section{Measures are Pearson's correlation coefficients ( $p$ values)}

ACQ, Asthma Control Questionnaire; GSAQ, GERD Symptoms Assessment Questionnaire; SABA, short-acting $\beta$ agonist use; SOB, shortness of breath.

Dark grey boxes indicate $p$ value significance $<0.01$, light grey boxes indicate $p$ value significance $<0.05$.

Bolded values represent $\mathrm{R}$ values $\geq 0.750$. Woken - 'On average, during the past week, how often were you woken by your asthma during the night?' Morning - 'On average, during

the past week, how bad were your asthma symptoms when you woke up in the morning?' Activities-'In general, during the past week, how limited were you in your activities because of your asthma?' SOB-'In general, during the past week, how much shortness of breath did you experience because of your asthma?' Wheeze- 'In general, during the past week, how much time did you wheeze?' SABA-'On average, during the past week, how many puffs/inhalations of short-acting bronchodilator have you used each day?' FEV1-FEV1 per cent predicted subscale of ACQ represented by a 7-point ordinal scale, FEV1\%-FEV1 per cent predicted. Subscales are in italics.

underrepresented the association between GOR and asthma symptoms commonly cited in asthmatics because this replicate cohort excluded children with significant past GORS.

Our study showed that GORS, particularly among obese asthmatics, are important to patients and negatively affect perceptions of asthma control, despite lung function being better and airway responsiveness being less. GORS are also extremely common in obese children. This study suggests that GORS may not always (or even often) act by commonly cited mechanisms in inducing the perception of asthma symptoms. For these patients, the symptoms contribute to poor asthma control according to validated measures. Therefore, the GOR-asthma relationship should be studied more in-depth in the context of symptom perception, attribution and management. GOR may not trigger asthma from a strictly pathophysiological perspective, but it appears to be driving patient-reported symptoms, particularly in obese children who experience a greater GORS burden. The two asthma control measures used in this study (ACQ, ACT) are almost exclusively based on patient perceptions, and are two of the most commonly used and wellvalidated tools. However, they do not always correlate well with other measures of asthma severity. Because clinics around the world use these types of patient-reported symptom questionnaires to guide management, patient perception is reality and

Table 5 Correlation coefficients between asthma and GORS subscales in lean children

\begin{tabular}{|c|c|c|c|c|c|c|c|c|c|c|}
\hline & ACQ & Woken & Morning & Activities & $S O B$ & Wheeze & $S A B A$ & FEV1 & FEV1\% & FEV1/FVC \\
\hline GSAQ score & $0.291(0.200)$ & $\begin{array}{l}0.345 \\
(0.125)\end{array}$ & $\begin{array}{l}0.587 \\
(0.005)\end{array}$ & $\begin{array}{l}0.041 \\
(0.859)\end{array}$ & $\begin{array}{l}0.424 \\
(0.056)\end{array}$ & $\begin{array}{l}0.259 \\
(0.193)\end{array}$ & $\begin{array}{l}0.086 \\
(0.710)\end{array}$ & $\begin{array}{l}-0.329 \\
(0.157)\end{array}$ & $\begin{array}{l}0.422 \\
(0.057)\end{array}$ & $\begin{array}{l}0.325 \\
(0.150)\end{array}$ \\
\hline Abdominal pain & $-0.047(0.848)$ & & & & & & & & & \\
\hline Chest pain/heartburn & $0.039(0.873)$ & & & & & & & & & \\
\hline Difficulty swallowing & $0.494(0.032)$ & & & & & & & & & \\
\hline Nausea & $0.354(0.137)$ & & & & & & & & & \\
\hline $\begin{array}{l}\text { Vomiting/ } \\
\text { regurgitation }\end{array}$ & $0.103(0.675)$ & & & & & & & & & \\
\hline Burping/belching & $0.173(0.478)$ & & & & & & & & & \\
\hline $\begin{array}{l}\text { Choking when } \\
\text { eating }\end{array}$ & $-0.016(0.949)$ & & & & & & & & & \\
\hline Pain after eating & $-0.025(0.931)$ & & & & & & & & & \\
\hline
\end{tabular}

Measures are Pearson's correlation coefficients ( $p$ values).

ACQ, Asthma Control Questionnaire; GORS, gastro-oesophageal reflux symptom; GSAQ, GERD Symptoms Assessment Questionnaire; SABA, short-acting $\beta$ agonist; SOB, shortness of breath.

Dark grey boxes indicate $p$ value significance $<0.01$, light grey boxes indicate $p$ value significance $<0.05$. Bolded values represent $R$ values $\geq 0.750$. Woken-'On average, during the past week, how often were you woken by your asthma during the night?' Morning-'On average, during the past week, how bad were your asthma symptoms when you woke up in the morning?' Activities - In general, during the past week, how limited were you in your activities because of your asthma?' SOB-'In general, during the past week, how much shortness of breath did you experience because of your asthma?' Wheeze-'In general, during the past week, how much time did you wheeze?' SABA-'On average, during the past week, how many puffs/inhalations of short-acting bronchodilator have you used each day?' FEV1—FEV1 per cent predicted subscale of ACQ represented by a 7-point ordinal scale, FEV1\%-FEV1 per cent predicted. Subscales are in italics. 


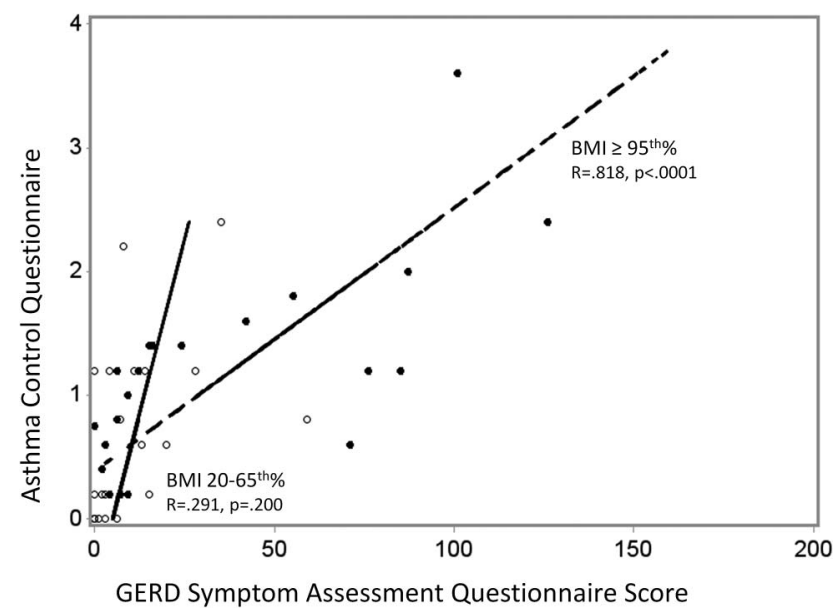

Figure 2 Relationship between gastro-oesophageal reflux symptom scores measured using the GERD Symptoms Assessment Questionnaire and asthma symptoms measured using the modified Asthma Control Questionnaire among lean and obese children.

drives treatment decisions and healthcare usage. Therefore, helping patients decipher GORS from true lower airway symptoms is critically important and will also reduce medication overuse and side effects, reduce the unnecessary escalation of controller drugs and reduce unnecessary usage for asthma. This should become an important focus of asthma self-management education. Especially for obese patients, questionnaires that query symptoms that are more specific to asthma ('whistling in the chest') may improve the accuracy of symptom monitoring. Newer portable spirometers which can measure airflow obstruction at home may be a promising tool to reduce misattribution and improve self-management in the future.

These data are consistent with a cycle of symptom misattribution, starting with SABA overuse acting on the lower oesophageal sphincter and promoting GORS which create chest symptoms, additional SABA use and GORS. This is supported by our recent finding that obese asthmatics self-medicate with SABA significantly more than leans. ${ }^{14}$ SABA use among obese adolescents may be unhelpful much of the time and occasionally leading to side effects. Better symptom training for asthmatics, especially those with obesity and GOR may improve management and reduce side effects and usage. Limitations of the current study included the relatively small size and power to uncover statistical interactions, exclusion of significant GOR from the replicate cohort and lack of participant dietary information. The replicate cohort was enriched with youths less apt to identify and report GOR and thus may have underrepresented the association between GORS and asthma symptom in all asthmatics. Differences in fat intake by obesity status could affect both GSAQ, airway neutrophilia and responses to SABA. $^{44}$ Diet alone is unlikely to completely explain the GSAQ-asthma association, since greater GOR secondary to diet would also be expected to impair lung response which we did not see.

A third explanation requires consideration. We speculate that for most otherwise healthy children, mild-to-moderate GOR does not frequently cause bronchospasm, but rather obscures and negatively influences perceptions of asthma severity. Anxiety was more prevalent in the highest BMI group and has been linked to greater asthma symptom reporting. Since GOR worsens health-related quality-of-life, ${ }^{45}$ it may also negatively bias an adolescent's perception of asthma control but would leave lung function unaffected. This explanation is consistent with the findings of an inverse relationship between GORS and lung function. Further supporting this hypothesis is the fact that obese children have distinct perceptions of symptoms. We and others have previously reported that obese children with asthma have heightened airway perception and a heightened sense of dyspnoea which is not completely explained by disease severity. ${ }^{46}$ On account of chest and abdominal compression and altered dietary habits, obese children experience more oesophageal reflux which leads to stimulation of the upper oesophagus and hypopharynx, throat-clearing, coughing and sensations in the throat and chest which are worrisome to the child. To understand and address the excess symptom reporting and usage experienced by obese asthmatics, more specific and accurate measures of asthma control may be needed. Interventions focused on helping obese patients decipher true asthma from co-morbidities will improve disease self-management, empowerment and patient-satisfaction, and reduce medication side effects and healthcare usage.

\section{Author affiliations}

'Division of Pulmonary \& Sleep Medicine, Nemours Children's Hospital, Orlando, Florida, USA

${ }^{2}$ Department of Biomedical Research, Center for Pediatric Research, Alfred I. DuPont Hospital of Children, Wilmington, Delaware, USA

${ }^{3}$ Department of Epidemiology, Johns Hopkins Bloomberg School of Public Health, Baltimore, Maryland, USA

${ }^{4}$ Division of Pediatric Respiratory Medicine \& Allergy, University of Virginia School of Medicine, Charlottesville, Virginia, USA

${ }^{5} \mathrm{GI}$ Care for Kids, Children's Center for Digestive Healthcare, Atlanta, Georgia, USA

${ }^{6}$ Pulmonary and Critical Care Medicine, Johns Hopkins University School of Medicine, Baltimore, Maryland, USA

${ }^{7}$ Center for Pharmacogenomics \& Translational Research, Nemours Children's Clinic, Jacksonville, Florida, USA

Funding Supported by Grants from the Nemours Foundation, the National Heart Lung and Blood Institute (K23HL096838-06 JEL; U01HL080450-01 JTH/WGT), Office of Dietary Supplements (K23HL096838-06 JEL), and the American Lung Association.

Competing interests None declared.

Ethics approval Nemours IRB \#2 (IORG \# 00000998) FWA 00000293.

Provenance and peer review Not commissioned; externally peer reviewed.

\section{REFERENCES}

1 Black MH, Zhou H, Takayanagi M, et al. Increased asthma risk and asthma-related health care complications associated with childhood obesity. Am J Epidemiol 2013;178:1120-8.

2 Taylor B, Mannino D, Brown C, et al. Body mass index and asthma severity in the National Asthma Survey. Thorax 2008;63:14-20.

3 Quinto $\mathrm{KB}$, Zuraw BL, Poon $\mathrm{KY}$, et al. The association of obesity and asthma severity and control in children. J Allergy Clin Immunol 2011;128:964-9.

4 Borrell LN, Nguyen EA, Roth LA, et al. Childhood obesity and asthma control in the GALA II and SAGE II studies. Am J Respir Crit Care Med 2011;187:697-702.

5 Forno $E$, Lescher $R$, Strunk $R$, et al. Decreased response to inhaled steroids in overweight and obese asthmatic children. J Allergy Clin Immunol 2011;127:741-9.

6 Ross KR, Hart MA, Storfer-Isser A, et al. Obesity and obesity related co-morbidities in a referral population of children with asthma. Pediatr Pulmonol 2009;44:877-84

7 Dixon AE, Shade DM, Cohen RI, et al. Effect of obesity on clinical presentation and response to treatment in asthma. J Asthma 2006;43:553-8.

8 Tantisira KG, Litonjua AA, Weiss ST, et al. Association of body mass with pulmonary function in the Childhood Asthma Management Program (CAMP). Thorax 2003;58:1036-41.

9 Sah PK, Gerald Teague W, Demuth KA, et al. Poor asthma control in obese children may be overestimated because of enhanced perception of dyspnea. J Allergy Clin Immunol Pract 2013;1:39-45.

10 Stordal K, Johannesdottir GB, Bentsen BS, et al. Asthma and overweight are associated with symptoms of gastro-oesophageal reflux. Acta Paediatr 2006;95:1197-201.

11 Jacobson BC, Somers SC, Fuchs CS, et al. Body-mass index and symptoms of gastroesophageal reflux in women. N Engl J Med 2006;354:2340-8. 
12 Hampel H, Abraham NS, El-Serag HB. Meta-analysis: obesity and the risk for gastroesophageal reflux disease and its complications. Ann Intern Med 2005;143:199-211.

13 Debley JS, Carter ER, Redding GJ. Prevalence and impact of gastroesophageal reflux in adolescents with asthma: a population-based study. Pediatr Pulmonol 2006;41:475-81

14 Lang JE, Hossain MJ, Lima JJ. Overweight children report qualitatively distinct asthma symptoms: analysis of validated symptom measures. J Allergy Clin Immunol 2015;135886-93.e3.

15 Thakkar K, Boatright RO, Gilger MA, et al. Gastroesophageal reflux and asthma in children: a systematic review. Pediatrics 2010;125:e925-30.

16 El-Serag HB, Gilger M, Kuebeler M, et al. Extraesophageal associations of gastroesophageal reflux disease in children without neurologic defects. Gastroenterology 2001;121:1294-9.

17 Blake K, Teague WG. Gastroesophageal reflux disease and childhood asthma. Curr Opin Pulm Med 2013;19:24-9.

18 GINA. Global Strategy for Asthma Management and Prevention (Revised 2014), 2014:1-148.

19 Schan CA, Harding SM, Haile JM, et al. Gastroesophageal reflux-induced bronchoconstriction. An intraesophageal acid infusion study using state-of-the-art technology Chest 1994;106:731-7.

20 Andersen LI, Schmidt A, Bundgaard A. Pulmonary function and acid application in the esophagus. Chest 1986;90:358-63.

21 Harding SM, Guzzo MR, Richter JE. 24-h esophageal pH testing in asthmatics: respiratory symptom correlation with esophageal acid events. Chest 1999;115:654-9.

22 Weinberger M, Abu-Hasan M. Perceptions and pathophysiology of dyspnea and exercise intolerance. Pediatr Clin North Am 2009;56:33-48, ix.

23 Seear M, Wensley $D$, West $N$. How accurate is the diagnosis of exercise induced asthma among Vancouver schoolchildren? Arch Dis Child 2005;90:898-902.

24 Lacy BE, Mathis C, DesBiens J, et al. The effects of nebulized albuterol on esophageal function in asthmatic patients. Dig Dis Sci 2008;53:2627-33.

25 Crowell MD, Zayat EN, Lacy BE, et al. The effects of an inhaled beta(2)-adrenergic agonist on lower esophageal function: a dose-response study. Chest 2001;120:1184-9.

26 Holbrook JT, Wise RA, Gold BD, et al. Lansoprazole for children with poorly controlled asthma: a randomized controlled trial. JAMA 2012;307: 373-81.

27 Castro M, King TS, Kunselman SJ, et al. Effect of vitamin D3 on asthma treatment failures in adults with symptomatic asthma and lower vitamin D levels: the VIDA randomized clinical trial. JAMA 2014;311:2083-91.

28 Juniper EF, O'Byrne PM, Guyatt GH, et al. Development and validation of a questionnaire to measure asthma control. Eur Respir J 1999;14:902-7.

29 Schatz M, Sorkness CA, Li JT, et al. Asthma Control Test: reliability, validity, and responsiveness in patients not previously followed by asthma specialists. J Allergy Clin Immunol 2006;117:549-56.
30 Nathan RA, Sorkness CA, Kosinski M, et al. Development of the asthma control test: a survey for assessing asthma control. I Allergy Clin Immunol 2004;113:59-65.

31 Juniper $\mathrm{EF}$, Guyatt $\mathrm{GH}$, Feeny $\mathrm{DH}$, et al. Measuring quality of life in children with asthma. Qual Life Res 1996;5:35-46.

32 Juniper EF, Guyatt GH, Willan A, et al. Determining a minimal important change in a disease-specific Quality of Life Questionnaire. J Clin Epidemiol 1994;47:81-7.

33 Juniper $E F$, Guyatt $G H$, Feeny $D H$, et al. Measuring quality of life in the parents of children with asthma. Qual Life Res 1996;5:27-34.

34 Deal L, Gold BD, Gremse DA, et al. Age-specific questionnaires distinguish GERD symptom frequency and severity in infants and young children: development and initial validation. J Pediatr Gastroenterol Nutr 2005;41:178-85.

35 Miller MR, Hankinson J, Brusasco V, et al. Standardisation of spirometry. Eur Respir J 2005;26:319-38.

36 Wanger J, Clausen JL, Coates A, et al. Standardisation of the measurement of lung volumes. Eur Respir J 2005;26:511-22.

37 Oostveen $\mathrm{E}$, MacLeod $\mathrm{D}$, Lorino $\mathrm{H}$, et al. The forced oscillation technique in clinical practice: methodology, recommendations and future developments. Eur Respir J 2003;22:1026-41.

38 American Thoracic Society; European Respiratory Society. ATS/ERS recommendations for standardized procedures for the online and offline measurement of exhaled lower respiratory nitric oxide and nasal nitric oxide, 2005. Am J Respir Crit Care Med 2005;171:912-30.

39 Crapo RO, Casaburi R, Coates AL, et al. Guidelines for methacholine and exercise challenge testing-1999. This official statement of the American Thoracic Society was adopted by the ATS Board of Directors, July 1999. Am J Respir Crit Care Med 2000;161:309-29.

40 Zerbib F, Guisset $\mathrm{O}$, Lamouliatte $\mathrm{H}$, et al. Effects of bronchial obstruction on lower esophageal sphincter motility and gastroesophageal reflux in patients with asthma. Am J Respir Crit Care Med 2002;166:1206-11.

41 Kiljander TO, Salomaa ER, Hietanen EK, et al. Gastroesophageal reflux and bronchial responsiveness: correlation and the effect of fundoplication. Respiration 2002;69:434-9.

42 Allen JL, Wohl ME. Pulmonary function in older children and young adults with gastroesophageal reflux. Clin Pediatr (Phila) 1986;25:541-6.

43 Wu DN, Tanifuji Y, Kobayashi H, et al. Effects of esophageal acid perfusion on airway hyperresponsiveness in patients with bronchial asthma. Chest 2000;118:1553-6.

44 Wood LG, Garg ML, Gibson PG. A high-fat challenge increases airway inflammation and impairs bronchodilator recovery in asthma. J Allergy Clin Immunol 2011;127:1133-40.

45 Varni JW, Bendo CB, Nurko S, et al. Health-related quality of life in pediatric patients with functional and organic gastrointestinal diseases. J Pediatr 2015;166:85-90.

46 Lang JE, Hossain J, Dixon AE, et al. Does age impact the obese asthma phenotype? Longitudinal asthma control, airway function, and airflow perception among mild persistent asthmatics. Chest 2011;140:1524-33. 